normally increased during acute hypoglycaemia, cerebral autoregulation may be impaired in diabetic patients. ${ }^{+}$The development of focal neurological signs during hypoglycaemia suggests that regional changes in vascular perfusion occur within the brain as a result of vascular spasm or localised atherosclerosis. ${ }^{1}$ These effects might be explained by selective neuronal vulnerability, and the cerebral cortex seems to be more prone to glucopenia if previously affected by ischaemia.

Loss of the autonomic warning symptoms of hypoglycaemia occurs in many patients who have had insulin dependent diabetes for a long time. The mechanism for this remains uncertain, ${ }^{+}$and it is difficult to counteract unless patients can learn to recognise early neuroglycopenia. In our case the consistent and reproducible neurological signs associated with hypoglycaemia alerted the patient to

the presence of neuroglycopenia. This restored his ability to detect impending severe hypoglycaemia and prevent more profound glucopenia by taking glucose. Retraining diabetic patients to identify neuroglycopenic symptoms may be one method of coping with unawareness of hypoglycaemia.

1 Montgomery BM, Pinner CA. Transient hypoglycemic hemiplegia. Arch Inter Med 1964;114:680-4.

Lawrence RD. Hemiplegia in a diabetic producing unilateral peripheral neuritis and hypoglycaemic attacks. Lancet 1967; i:1321-2.

3 Silas JH, Grant DS, Maddocks JL. Transient hemiparetic attacks due to unrecognised nocturnal hypoglycaemia. Br Med $\mathcal{F} 1981 ; 282: 132-3$.

+ Frier BM. Hypoglycaemia and diabetes. Diabetic.Med 1986;3:513-25.

5 Neil HAW, Gale EAM, Hamilton SJC, Lopez-Espinoza I, Kaura R, McCarthy ST. Cerebral blood flow increases during insulin-induced hypoglycaemia in type 1 (insulin-dependent) diabetic patients and control subjects. Diabetologia 1987;30:305-9.

Accepted 27 Nowember 1989 .

\section{Does vasectomy accelerate testicular tumour? Importance of testicular examinations before and after vasectomy}

\author{
A R J Cale, M Farouk, R J Prescott, \\ I W J Wallace
}

Bangour General Hospital, West Lothian, EH52 6LR A R J Cale, FRCSED, registrar $M$ Farouk, FRCSED, registrar I W J Wallace, FRCS, consultant surgeon

Medical Statistics Unit, Edinburgh University, Edinburgh EH8 9AG

$\mathrm{R} J$ Prescott, PHD, director

Correspondence to:

Mr A R J Cale, Department of Cardiothoracic Surgery, Royal Infirmary of Edinburgh, Edinburgh EH3 9YW.

Br.Med f 1990;300:370 at Bangour General Hospital in the past 10 years.

\section{Patients, methods, and results}

The incidence of testicular tumour in Scotland has risen over the past decade. During this period vasectomy has become a more popular form of contraception. We conducted a retrospective study of all patients in whom testicular tumour had been diagnosed

Testicular tumours were detected in 37 patients aged under 60 attending the hospital, the only hospital serving the West Lothian district, during 1977-87. During this period 3079 men had a vasectomy, of whom eight were subsequently found to have testicular tumours. The average time between vasectomy and the diagnosis of a tumour was 1.9 years (range $0.25-4$ years). Data provided by the information and statistics division of the Common Services Agency of the Scottish health service showed that less than $0.5 \%$ of vasectomies were performed outside the district.

The table shows the number of cases of testicular tumour in patients aged 20-59 and the age specific incidence in West Lothian over the study period calculated from population figures. ${ }^{1}$ The incidences, together with the numbers of patient years of risk in the group who had had a vasectomy, were used to calculate the expected number of testicular tumours in that group (1.9); the observed number was eight.

Thus the standardised incidence ratio for patients who had had a vasectomy was $4 \cdot 2$ (95\% confidence interval 1.8 to $8 \cdot 2$ ). The absolute annual incidence of

Incidence of testicular tumour in West Lothian, 1977-87

\begin{tabular}{lccccccc}
\hline & \multicolumn{3}{c}{ All men } & & & \multicolumn{3}{c}{ Men who had had vasectomies } \\
\cline { 2 - 3 } \cline { 7 - 8 } $\begin{array}{c}\text { Age } \\
\text { (years) }\end{array}$ & $\begin{array}{c}\text { Patient years } \\
\text { of risk }\end{array}$ & No of cases & $\begin{array}{c}\text { No/100 000 } \\
\text { men/year }\end{array}$ & & $\begin{array}{c}\text { Patient years } \\
\text { of risk }\end{array}$ & $\begin{array}{c}\text { Expected No } \\
\text { of cases }\end{array}$ & $\begin{array}{c}\text { Observed No } \\
\text { of cases }\end{array}$ \\
\hline $20-$ & 65100 & 5 & $7 \cdot 7$ & & 59 & 0.0 & 0 \\
$25-$ & 57500 & 5 & $8 \cdot 7$ & & 1253 & $0 \cdot 1$ & 0 \\
$30-$ & 58800 & 9 & $15 \cdot 3$ & & 4497 & $0 \cdot 7$ & 6 \\
$35-$ & 55300 & 7 & $12 \cdot 7$ & & 4523 & $0 \cdot 6$ & 1 \\
$40-$ & 47100 & 7 & $14 \cdot 9$ & & 2966 & $0 \cdot 4$ & 1 \\
$45-$ & 42100 & 3 & $7 \cdot 1$ & & 1270 & $0 \cdot 1$ & 0 \\
$50-$ & 37200 & 1 & $2 \cdot 7$ & & 372 & $0 \cdot 0$ & 0 \\
$55-59$ & 33700 & 0 & 0 & & 151 & $0 \cdot 0$ & 0 \\
\hline All ages & 396800 & 37 & $9 \cdot 3$ & & 15091 & 1.9 & 8 \\
\hline
\end{tabular}

testicular tumour in men who have had a vasectomy is $53 / 100000$ men

\section{Comment}

Our study suggests an association between vasectomy and subsequent development of testicular tumours. Immunological and pathophysiological effects have been shown to occur after vasectomy. ${ }^{2}$ Thornhill et al also observed an increased incidence of testicular tumours in men who had had vasectomies but suggested that the tumours had been present at the time of the procedure. ${ }^{3}$ The time interval between vasectomy and diagnosis of a testicular tumour in our study would seem to support this hypothesis as new tumours are unlikely to arise in such a short period.

Other workers ${ }^{4}$ and four large multicentre studies have not shown an association between vasectomy and testicular cancer. The combined power of the multicentre studies to show a twofold increased incidence of testicular cancer, however, was only $0 \cdot 2^{5}$ because of the low incidence of testicular tumours. Only a very large cohort study would be able to discover whether a true association exists.

We suggest that vasectomy accelerates the development of a palpable tumour from a carcinoma in situ or that palpable tumours are overlooked at the time of vasectomy. Thorough examination before a vasectomy should pick up most palpable tumours, and carcinomas could be detected by cytological examination of semen expressed from the proximal end of each vas during the vasectomy. Alternatively, men could be screened by a single examination 12 to 18 months after the vasectomy. Swelling after a vasectomy is common, and if it persists it may delay the diagnosis of tumour.

Our results require clarification from a large prospective study and analysis of confounding factors such as smoking and social class. The possibility of vasectomy affecting the aetiology of testicular malignancy is important especially in view of the current trend towards male sterilisation.

We thank Dr F G R Fowkes, department of community medicine, Edinburgh University and Mr P M King, department of surgery, Eastern General Hospital, Edinburgh, for their help.

1. Registrar General for Scotland. Annual report. Edinburgh: HMSO, 1978-88

2 Rumke PH, Hellema HWJ. Immunological studies in the long term follow-up of vasectomised men. In: Lepow IH, Crozier R, eds. Vasectomy: immunologic and pathophysiologic effects in animals and man. New York: Academic Press, 1979

Thornhill JA, Butler M, Fitzpatrick JM. Could vasectomy accelerate testicular cancer? The importance of prevasectomy examination. Br f Urol 1987;59:367. Moss AR, Osmond D, Bacchetti P, et al. Hormonal risk factors in testicular cancer: a case control study. Am $\mathcal{F}$ Epidemiol 1986;124:39-52.

5 Strader $\mathrm{CH}$, Weiss NS, Daling JR. Vasectomy and the incidence of testicular cancer. Am 7 Epidemiol 1988;128:56-63. 